\title{
Effect of Repainting Process on Atmospheric Corrosion Behavior of Perforated Panels
}

\author{
Motoki Kuratani ${ }^{1}$, Kenji Yamakawa ${ }^{2}$, Ryuji Kurono ${ }^{3}$, Yuma Kano' ${ }^{1}$, Takato Sasaki ${ }^{1}$, \\ Yutaka Yamada ${ }^{1,4}$, Osamu Sakurada1* $^{*}$ \\ ${ }^{1}$ Department of Chemistry and Biomolecular Science, Faculty of Engineering, Gifu University, Gifu-shi, Gifu, Japan \\ ${ }^{2}$ Daiwa Inc., Kakamigahara-shi, Gifu, Japan \\ ${ }^{3}$ Tsutsui Industries, Handa-shi, Aichi, Japan \\ ${ }^{4}$ Daiwa Techno Co., Ltd., Gifu-shi, Gifu, Japan \\ Email: z4524032@edu.gifu-u.ac.jp, yamakawa@daiwa-net.com,r-kurono@tsutsuik.co.jp, a4524025@edu.gifu-u.ac.jp, \\ a4524033@edu.gifu-u.ac.jp, y.yamada@daiwatec.com, *sakurada@gifu-u.ac.jp
}

How to cite this paper: Kuratani, M., Yamakawa, K., Kurono, R., Kano, Y., Sasaki, T., Yamada, Y. and Sakurada, O. (2021) Effect of Repainting Process on Atmospheric Corrosion Behavior of Perforated Panels. Materials Sciences and Applications, 12, 534-541.

https://doi.org/10.4236/msa.2021.1211035

Received: October 15, 2021

Accepted: November 21, 2021

Published: November 24, 2021

Copyright $\odot 2021$ by author(s) and Scientific Research Publishing Inc. This work is licensed under the Creative Commons Attribution International License (CC BY 4.0).

http://creativecommons.org/licenses/by/4.0/

(c) (i) Open Access

\begin{abstract}
Steel structures are often painted to protect against corrosion. Repainting is one of the most important factors in maintaining the corrosion protection function of the coating. Various factors affect the life of the coating film, such as the surface preparation, the type of coating, and the number of coats. Surface preparation is important for the life of the coating film. However, appropriate surface treatment is difficult due to the complex shape of perforated panels, and it has been confirmed that corrosion progresses from the machined area. Therefore, appropriate pretreatment of the machined area is important for corrosion prevention. In this study, we investigated the effects of the repainting process on the atmospheric corrosion behavior of perforated panels. To reproduce the repainting process, a number of pretreatments were performed, such as salt spraying, blasting, and zinc phosphate treatment. In the salt spray test after pretreatment and painting, the corrosion progressed in cases with no zinc phosphate treatment and those left untreated for $48 \mathrm{~h}$ before painting. In addition, the coating film on the processed area was confirmed to be thin. These results suggested that appropriate pretreatment and sufficient thickness of the coating on the machined area would affect the occurrence of corrosion.
\end{abstract}

\section{Keywords}

Repaint, Perforated Panel, Pretreatment, Machined Area, Painting Thickness

\section{Introduction}

Steel structures are often painted to protect against corrosion, and repainting is 
one of the most important factors in maintaining the corrosion protection function of the coating. If the coating can be maintained in a stable condition for a long time, the number of times repainting will be necessary during the life cycle could be reduced, and thus reduce maintenance costs [1] [2] [3] [4]. A number of factors affect the life of the coating film, including the surface preparation, the type of coating, and the number of coats, and it has been demonstrated that surface preparation is important for prolonging the life of the coating film [5]. However, in real-world application, the entire repaint process is rarely completed in a single factory, and so it may be unclear whether appropriate treatments were carried out. Although dependent on the weather, temperature, and humidity, it is usually recommended to paint within 4 hours after pretreatment [6]. Thus, if the transportation time of the material between factories is excessive, the pretreatment would become ineffectual. In the field of architecture, perforated panels, which are often used for the exterior walls of apartment buildings as well as corporate and social infrastructure facilities, are also painted for protection against corrosion. In addition to their decorative purpose, perforated panels have advantages, such as providing shade from the sun, reducing noise, and saving energy [7] [8] [9]. However, corrosion is known to progress in the machined area due to the residual stress of the punching process, and rust often becomes apparent from the edge of the machined area due to deterioration of the coating film [1] [3] [10] [11] [12] [13]. Machined parts are often not flat but complex in shape, and it is difficult to obtain a sufficient coating thickness. Therefore, in the painting of steel structures, especially in the repainting process, it is important to perform appropriate pretreatment before painting and to obtain a sufficient coating thickness on the machined parts.

In this study, we investigated the effects of the repainting process on the corrosion behavior of perforated panels.

\section{Experimental Methods}

\subsection{Specimens}

The specimens were perforated Steel Plate Cold Commercial (SPCC) sheets with a diameter of $20 \mathrm{~mm}$, which were pretreated by salt spraying, blasting, zinc phosphate treatment, and painting to reproduce the repainting process (Figure 1). The salt-sprayed specimens were used as rust specimens and the as-received specimens were used as new specimens. The unprocessed general area was referred to as the flat area, the perforated section as the whole area, and the perforated corner as the edge area. The painting thickness of the flat part was set to 60 mm using a thickness meter (DUALSCOPE MP0R; Kett Scientific Laboratory, Tokyo, Japan), and the time until painting was set to 4 or 48 hours. Specimens were sprayed with salt water (5\% $\mathrm{NaCl}$ aqueous solution) for 1600 hours at a temperature of $35^{\circ} \mathrm{C} \pm 1{ }^{\circ} \mathrm{C}$, and white alumina grids with grain sizes of 850 $1180 \mathrm{~mm}$ (hereafter referred to as \#20) and $600-850 \mathrm{~mm}$ (hereafter referred to as \#24) blended at a ratio of \#20: \#24=1:3 were blasted at $0.4 \mathrm{MPa}$. Table 1 


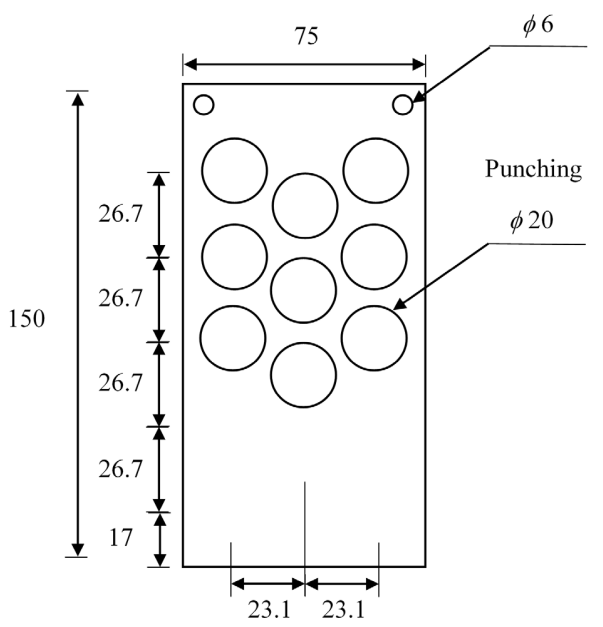

Figure 1. Geometry of the specimens (mm).

Table 1. Condition of specimens.

\begin{tabular}{ccccccc}
\hline No. & 1 & 2 & 3 & 4 & 5 & 6 \\
\hline Material & & Rust sample & & New sample \\
\hline Zinc phosphate treatment & $\bigcirc$ & $\bigcirc$ & $\times$ & $\times$ & $\bigcirc$ & $\times$ \\
Time to paint $[\mathrm{h}]$ & 4 & 48 & 4 & 48 & 4 & 4 \\
\hline
\end{tabular}

shows the preparation conditions for the specimens. The specimens were evaluated by visual inspection, examination of cross-sections, and scanning electron microscopy (SEM) (S-4300; Hitachi, Ibaraki, Japan) with energy dispersive X-ray spectrometry (EDX) (EX-220; Horiba, Kyoto, Japan), and the painting thickness was measured on the cross-sections.

\subsection{Salt Spray Test}

The salt spray test was carried out as described in Section 2.1 for 2 weeks, 1 month, and 2 months with a cycle of 5 days of salt spraying followed by 9 days of drying at room temperature with reference to environmental acceleration experiments [1] [2] [3].

\section{Results and Discussion}

\subsection{Evaluation of Specimens}

Figure 2 shows the appearance and SEM observations of each pretreatment process. The untreated specimens had rusted over the entire surface, and SEM showed unevenness caused by the rust. The surface of the blast-treated specimens was gray, and rust was not observed on visual inspection of SEM. After zinc phosphate treatment, the surface was gray-black, and SEM showed low surface roughness. After painting, the surface was smooth and shiny.

Figure 3 shows the results of SEM and EDX analysis of the cross-section of No. 1. From the observations of cross-sections, it was confirmed that the coating 


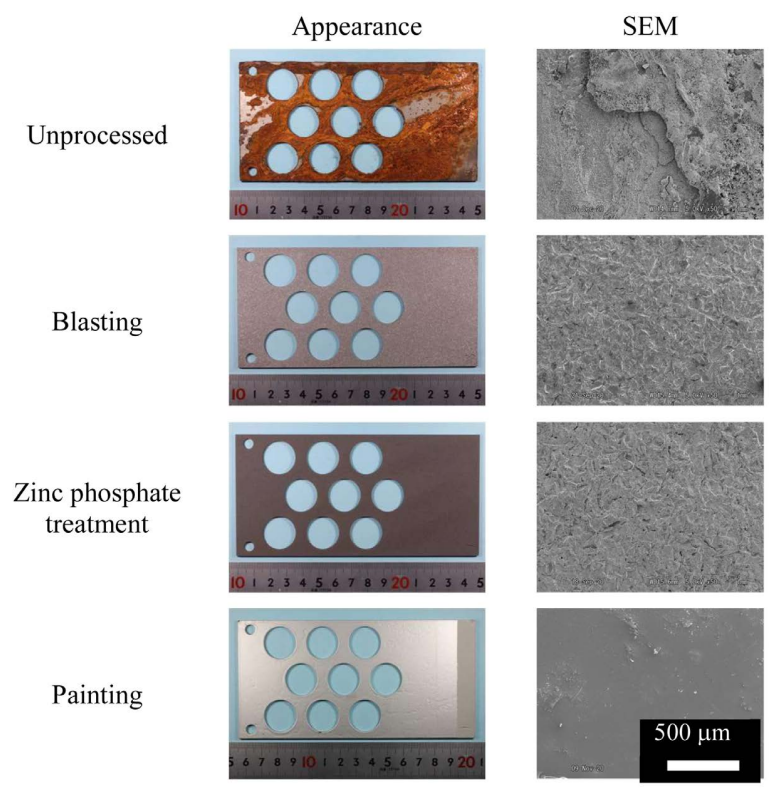

Figure 2. Observation of the appearances of each pretreatment process.

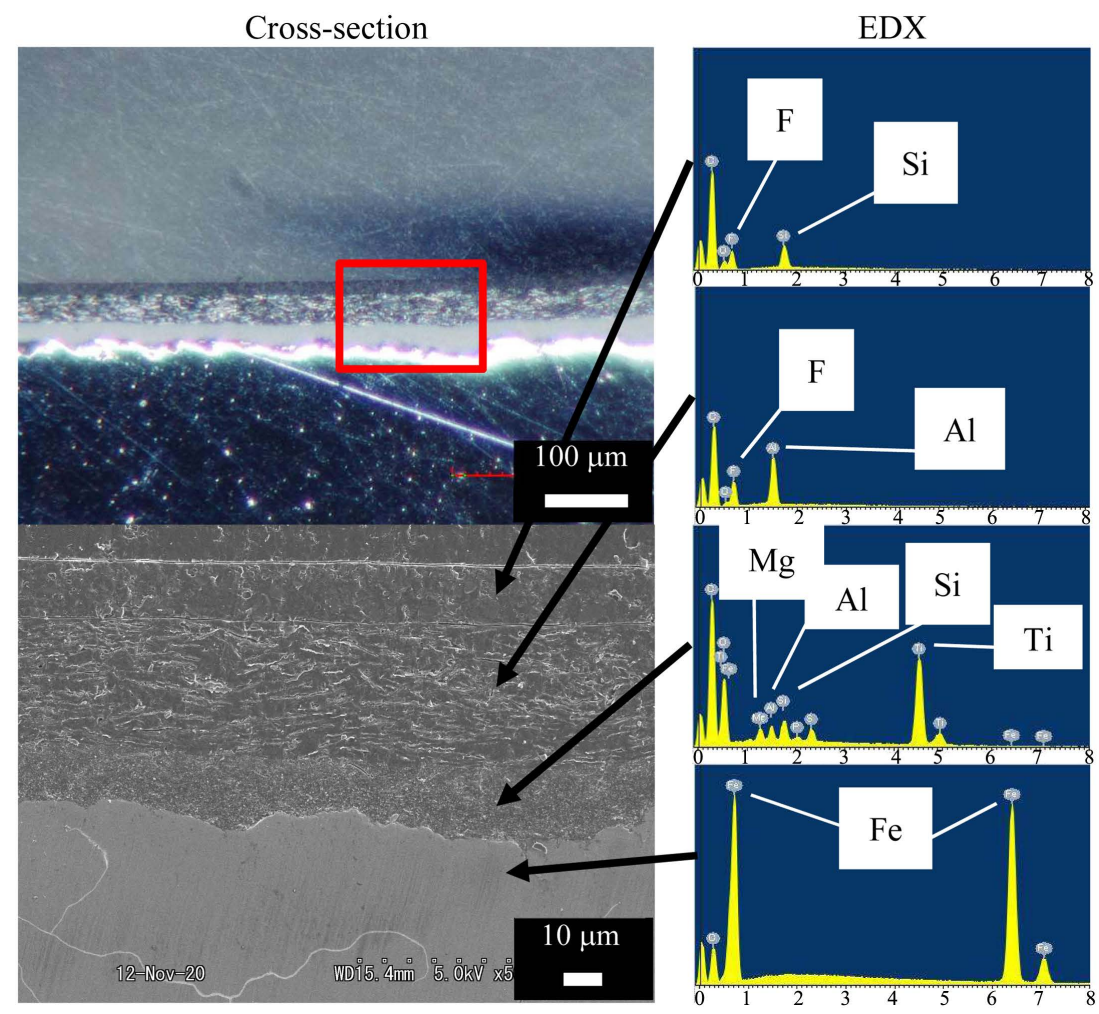

Figure 3. Observation of cross-sections and EDX analysis.

film had a three-layer structure. The first layer on the base iron was white layer composed mainly of Ti about $20 \mathrm{~mm}$ thick that was not uniform due to the unevenness of the base metal surface caused by blasting. The second layer was a silvery-white layer composed of $\mathrm{Al}$ and $\mathrm{F}$. There were horizontal streaks on the base material in the layer. The third layer, which was in contact with the outside 
air, was a black coating composed of Si, F, etc., with a thickness of about $20 \mathrm{~mm}$. The total thickness of the three layers was used as the painting thickness, and the thickness of each specimen was measured. Table 2 shows the film thickness of each part of the specimen. The painting thickness of the flat area was $>60 \mathrm{~mm}$ as measured with the thickness meter, and it was thought that the thickness meter displayed a value smaller than the actual thickness. On the other hand, the hole and edge areas were thinner than $60 \mathrm{~mm}$, less than half that of the flat area. The thinner film was thought to be associated with a greater water penetration rate, and the corrosion would therefore tend to progress from the hole and edge areas.

\subsection{Results of Salt Spray Test}

Table 3 shows the changes in the presence of corrosion after the salt spray test for each specimen. In cases No. 1 and No. 2, which were rust specimens and treated with zinc phosphate, corrosion was not observed regardless of the duration of the salt spray test for No. 1, in which the time until coating was 4 hours. However, for No. 2, in which the time until coating was 48 hours, corrosion was observed from 1 month after the salt spray test. In the case of No. 3 and No. 4, which were not treated with zinc phosphate, corrosion was observed after 2 weeks for No. 3 and after 1 month for No. 4. On the other hand, corrosion did not progress in the new specimens regardless of the pretreatment conditions. These observations confirmed the usefulness of zinc phosphate treatment and it was suggested that the rust was removed by the process of zinc phosphate treatment. As an example, Figure 4 shows the changes in No. 4 with time and the results of cross-section observation of the hole area. No corrosion was observed before the salt spray test, but after 2 weeks, corrosion was observed in the areas indicated by points, and the number of corrosion points tended to increase over time. The corrosion tended to progress from the upper part of the hole area. Observation of cross-sections of the holes confirmed that the corrosion progressed under the painted film. As corrosion progressed from the machined part, it was thought that the rust in the machined part was not sufficiently removed by blasting treatment. Figure 5 shows the results of SEM and EDX analysis of No. 4 after 2 months of salt spray test. EDX analysis confirmed that the corrosion progressed under the coating film because Ti was present covering the corrosion products. These results suggested that appropriate pretreatment, especially zinc phosphate treatment, and painting within 4 hours would prevent the

Table 2. Coating thickness of each part of the specimens.

\begin{tabular}{cccccccc}
\hline & No. & 1 & 2 & 3 & 4 & 5 & 6 \\
\hline $\begin{array}{c}\text { Coating } \\
\text { thickness } \\
{[\mathrm{mm}]}\end{array}$ & Flat part & 85 & 86 & 79 & 73 & 90 & 86 \\
& Hole part & 32 & 19 & 28 & 14 & 32 & 49 \\
\hline
\end{tabular}


Before test
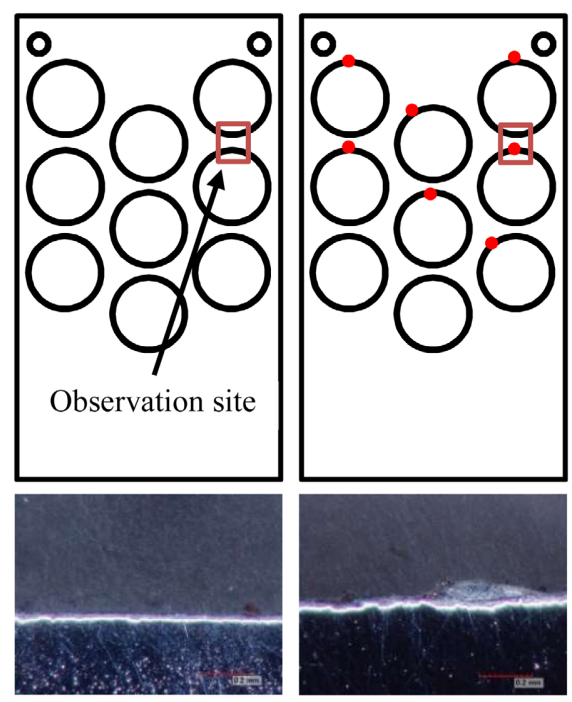

After 1 month
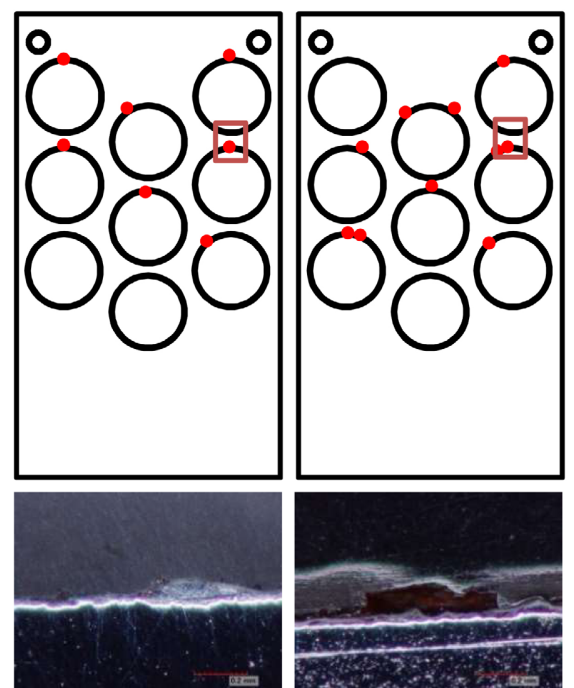
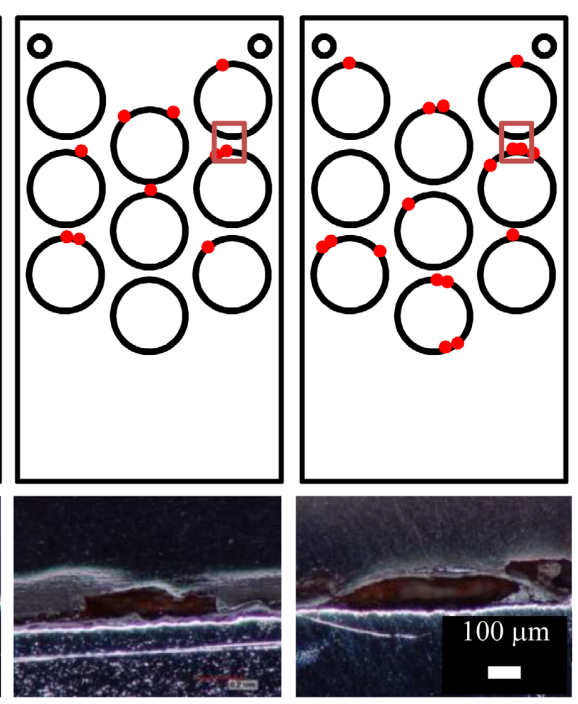

- Corrosion part

Figure 4. Changes in corrosion occurrence and observation of cross-sections (No. 4).

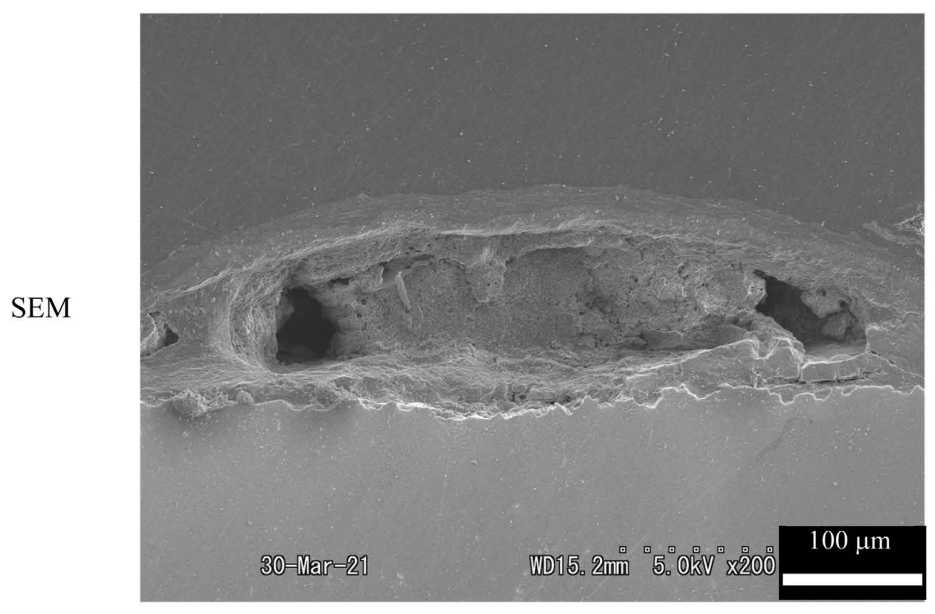

EDX
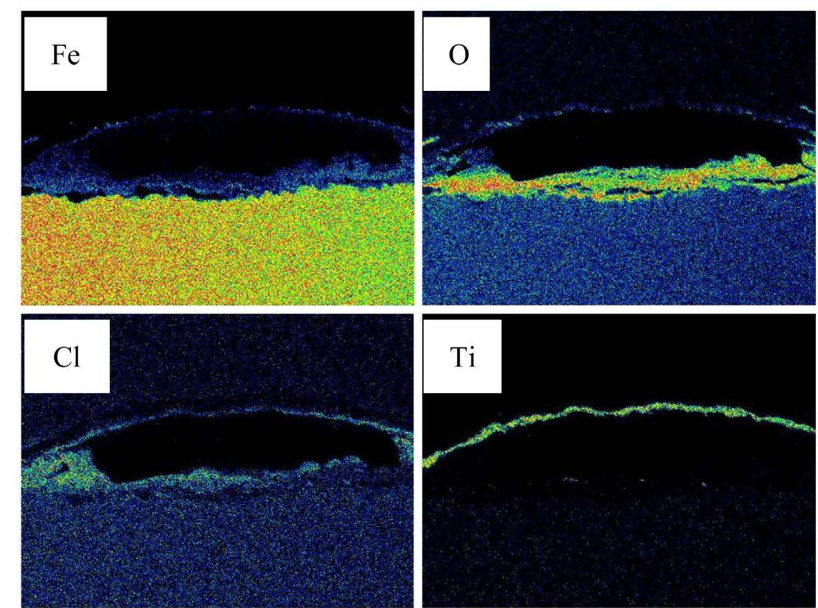

Figure 5. Results of EDX analysis of a cross-section of No. 4 after 2 months. 
Table 3. Occurrence of corrosion after salt spray test.

\begin{tabular}{|c|c|c|c|c|c|c|c|}
\hline \multicolumn{2}{|c|}{ No. } & 1 & 2 & 3 & 4 & 5 & 6 \\
\hline \multicolumn{2}{|c|}{ Material } & \multicolumn{4}{|c|}{ Rust sample } & \multicolumn{2}{|c|}{ New sample } \\
\hline \multicolumn{2}{|c|}{ Zinc phosphate treatment } & $\bigcirc$ & $\bigcirc$ & $x$ & $x$ & $\bigcirc$ & $x$ \\
\hline \multicolumn{2}{|c|}{ Time to paint $[\mathrm{h}]$} & 4 & 48 & 4 & 48 & 4 & 4 \\
\hline \multirow{4}{*}{$\begin{array}{l}\text { Salt spray } \\
\text { test period }\end{array}$} & Before test & (2) & () & (2) & (2) & (0) & (0) \\
\hline & After 2 weeks & () & () & (2) & $x$ & (2) & (0) \\
\hline & After 1 month & (2) & $\times$ & $x$ & $x$ & (2) & () \\
\hline & After 2 months & (2) & $x$ & $x$ & $x$ & (a) & (0) \\
\hline
\end{tabular}

(): No corrosion; $\times$ : Corrosion.

progression of corrosion when repainting perforated steel sheets. In addition, it was inferred that the film thickness affected the timing of corrosion appearance because the film thickness at the machined area was thin and corrosion was observed in this area.

\section{Conclusions}

The effects of repainting on the corrosion behavior of perforated panels were investigated in each process of repainting, and the following findings were obtained:

1) Appropriate pretreatment, especially zinc phosphate treatment and coating within 4 hours, was effective in inhibiting corrosion.

2) The thickness of the painting film on the machined area affected the timing of the appearance of corrosion.

In the future, we would like to study the appropriate pretreatment method and new painting method to obtain enough painting thickness.

\section{Conflicts of Interest}

The authors declare no conflicts of interest regarding the publication of this paper.

\section{References}

[1] Shimizu, Y., Itoh, Y. and Kim, I. (2007) Influence of Edge Treatment of Base Steel Plates on Corrosion Resistance of Coated Steel Bridges. Journal of Structural Engineering, 53, 825-833. https://doi.org/10.11532/structcivil.53A.825

[2] Itoh, Y., Tsubouchi, S. and Kim, I. (2008) Corrosion Deterioration Characteristics of Various Repainted Steels Considering Accelerated Exposure Test Results. Journal of Japan Society of Civil Engineers, 64, 556-570. https://doi.org/10.2208/jsceja.64.556

[3] Itoh, Y., Shimizu, Y. and Kitane, Y. (2010) Corrosion Resistance of Painted Steel Plate Edges Prepared with Different Corner Geometries Examined by Combined Cyclic Corrosion Test. Journal of Japan Society of Civil Engineers, 66, 68-78. 
https://doi.org/10.2208/jsceja.66.68

[4] Ogami, H., Fujii, K., Manabe, Y., Ota, K. and Yonekura, A. (2017) Applicability of a New Surface Preparation Method for Steel Structure Using Laser. Journal of Structural Engineering, 63, 476-482. https://doi.org/10.11532/structcivil.63A.476

[5] Japan Bridge Association Website (2005). https://www.jasbc.or.jp/QA/data/pdf/Q3-67_20050106.pdf

[6] Ishihara, T. (2017) The Current Issue Case Histories in Corrosion Failures Analysis and Corrosion Diagnostics. Techno Systems, Inc., 966.

[7] Yoshikawa, M., Asami, Y., Tabata, A. and Tomitaka, R. (2007) Study of Aerodynamic Noise Emitted from Perforated Metals. Report of Taisei Technology Center, 40, 1-6.

[8] Mironovs, V., Tatarinov, A. and Gorbacova, S. (2017) Expanding Application of Perforated Metal Materials in Construction and Architecture. Material Science and Engineering, 251, 2-9. https://doi.org/10.1088/1757-899X/251/1/012027

[9] Industrial Perforators Association (1993) Specifiers and Buyers Handbook for Perforated Metals. http://www.iperf.org/files/6213/9267/1671/IPA_Perforated_Metals_Handbook.pdf

[10] Kim, I. and Itoh, Y. (2007) Accelerated Exposure Tests as Evaluation Tool for Estimating Life of Organic Coatings on Steel Bridges. Corrosion Engineering, Science and Technology, 42, 242-252. https://doi.org/10.1179/174327807X214833

[11] Rumiche, F., Juarez, C. and Nuñez, R. (2019) Macro and Micro Scale Corrosion of 316L Stainless Steel: A Case Study of a Hole Plate. Journal of Failure Analysis and Prevention, 19, 1218-1224. https://doi.org/10.1007/s11668-019-00753-4

[12] Mahendra Babu, N.C., Jagadish, T., Ramachandra, K. and Sridhara, S.N. (2008) A Simplified 3-D Finite Element Simulation of Cold Expansion of a Circular Hole to Capture through Thickness Variation of Residual Stresses. Engineering Failure Analysis, 15, 339-348. https://doi.org/10.1016/j.engfailanal.2007.02.003

[13] Takakuwa, O. and Soyama, H. (2015) Effect of Residual Stress on the Corrosion Behavior of Austenitic Stainless Steel. Advances in Chemical Engineering and Science, 5, 62-71. https://doi.org/10.4236/aces.2015.51007 